\title{
Abscess and fistulae in Crohn's disease
}

\author{
DAVID M. STEINBERG ${ }^{1}$, W. TREVOR COOKE, AND J. ALEXANDER-WILLIAMS
}

From the Nutritional and Intestinal Unit, General Hospital, Birmingham

SUMMARY In a series of 360 patients with Crohn's disease $18 \%$ have developed a complication of abscess and/or fistula. Both complications can be spontaneous but more commonly occur in patients who have had a previous operation. There is a high incidence of fistula after laparotomy without resection of diseased bowel. Simple drainage of an abscess is usually followed by a fistula and fistulae do not close spontaneously. The optimal surgical treatment for fistula and for deep abscess is excision in continuity with the diseased segment of intestine.

This paper reports the incidence, natural history, and our experience in treating the complications of abdominal abscess and fistula in a series of patients with Crohn's disease. Perianal disease and early postoperative complications, settling on conservative measures, have been excluded from this study. We consider abscess and fistula to be part of the same pathological process, namely, the extramural extension of a fissure-ulcer. If this remains localized in an intraperitoneal space it forms an abscess, if it ulcerates into adjacent viscera or to the surface it becomes a fistula.

\section{Incidence}

Three hundred and sixty patients with Crohn's disease have been followed for a mean of 13 years. Abscess and/or fistulae have been found in 65 patients. For simplicity of analysis the two complications are considered separately.

Forty-four patients have had a total of 59 abscesses of which 33 were in the abdominal wall and 26 were found within the abdomen. Thirteen of these abscesses occurred spontaneously and the remainder in patients who had had a previous operation. Of the 13 patients presenting with a spontaneous abscess, three presented at the skin surface and required drainage, the remainder being found at laparotomy. Of these 10 spontaneous intraabdominal abscesses, seven were found in association with internal fistulae.

The time interval for presentation of an abscess after operation shows a wide scatter (fig 1) and 'D.M.S. Supported by a grant from the Raine Research Founda-
tion of the University of Western Australia.

Received for publication 17 July 1973.

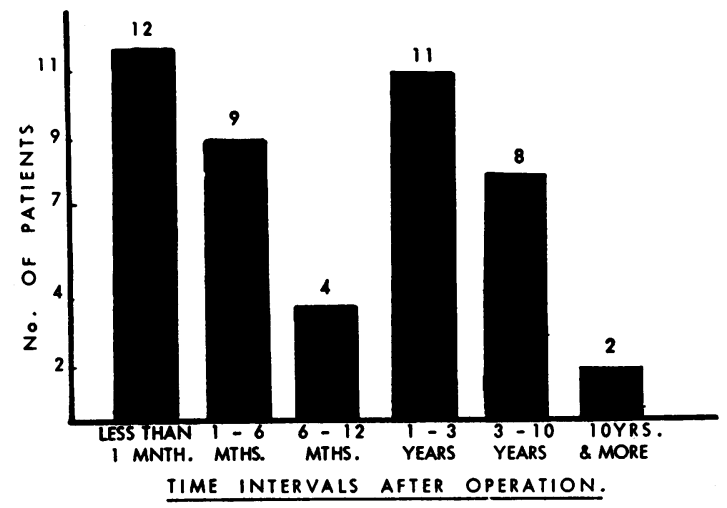

Fig 1 Histogram showing number of abscesses in time intervals after previous operations.

although some abscesses occur within a month of operation most present months or even years later. The majority of these abscesses have been shown to be due to recurrent disease. However, in three patients, two with pelvic and one with a subphrenic abscess, all of whom presented several years after operation, there was no evidence of recurrent disease and the abscesses must have been direct complications of these operations.

Forty-nine patients were found to have a total of 60 fistulae. The site of presentation has been classified as either externally to the skin or vagina -42 patients $(11 \%)$ or internally to another viscus18 patients $(5 \%)$. Thirty-six of the 42 external fistulae were in direct communication with the small bowel, whereas only six were involving the large intestine.

The number of fistulae and the years of occurrence are shown in figure 2. This is compared with the 


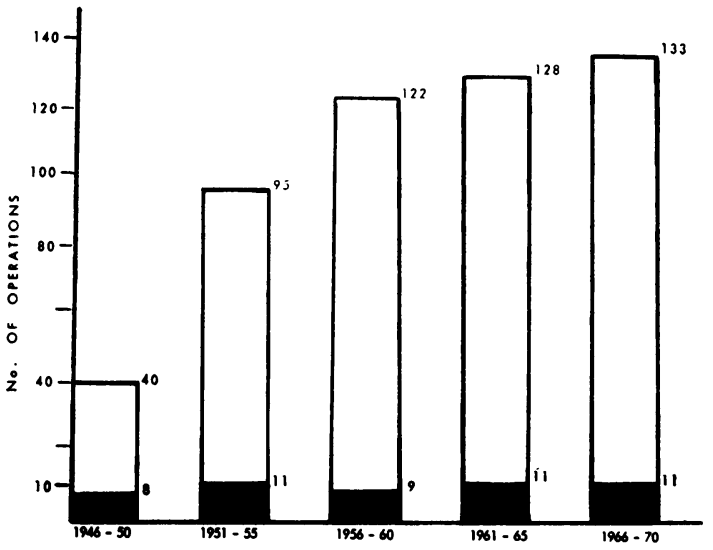

Fig 2 Histogram comparing fistulae with numbers of elective surgery for Crohn's disease in five-year intervals.

Open columns indicate the number of elective operations and the black columns the number of fistulae.

total number of elective operations, namely, resection and bypass, carried out between the years 1945 and 1970. These are considered in five-year intervals. Although the number of elective operations has increased considerably the number of fistulae has remained constant.

In this series of 60 fistulae, 13 occurred in patients who had had no previous laparotomy. The distribution of earlier operations in the remainder is shown in table I. Fistulae occurred 22 times after resection, eight after a bypass procedure, four after diagnostic laparotomy, and 13 times after appendicectomy. These absolute figures, however, are of little significance on considering the wide distribution of numbers in each operative group (fig 1). There was a $5 \%$ incidence after resection (417 operations), $13 \%$ after bypass (64), $11 \%$ after diagnostic laparotomy (35), and $24 \%$ after appendicectomy (54).

Ten of the 13 fistulae after appendicectomy occurred before 1955 and there has been none since 1965. However, only one appendicectomy has been

\begin{tabular}{llll}
\hline Type of Operation & $\begin{array}{l}\text { Total No. of } \\
\text { Operations }\end{array}$ & $\begin{array}{l}\text { Late Occurrence } \\
\text { of Fistula }\end{array}$ & $\begin{array}{l}\text { Incidence } \\
(\%)\end{array}$ \\
\hline $\begin{array}{l}\text { Resection } \\
\text { Bypass }\end{array}$ & 417 & 22 & 5 \\
$\begin{array}{l}\text { Diagnostic } \\
\text { laparotomy }\end{array}$ & 64 & 8 & 13 \\
$\begin{array}{l}\text { Appendicectomy } \\
\text { (5) }\end{array}$ & 54 & 4 & 11 \\
\hline
\end{tabular}

Table I Incidence of fistula after different operations for Crohn's disease

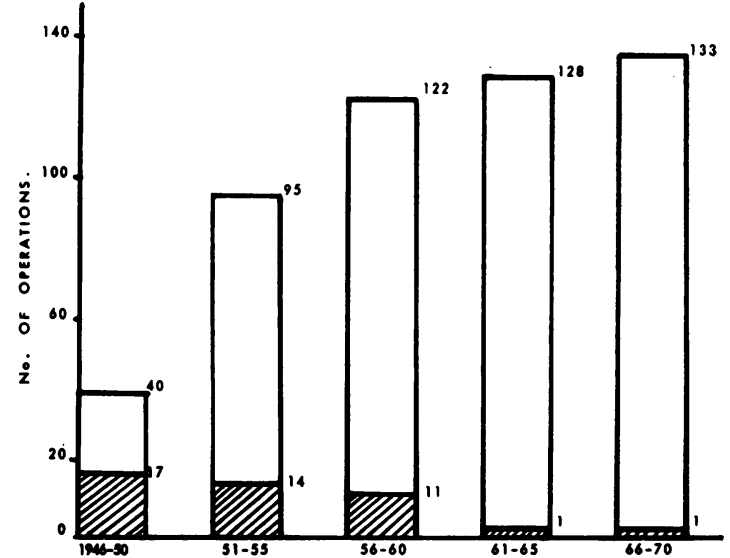

Fig 3 Histogram comparing appendicectomy in Crohn's disease with numbers of elective operations for Crohn's disease in five-year intervals.

Open columns indicate elective operation (resection and bypass) and hatched columns appendicectomy only.

carried out since 1965. The distribution of the 54 appendicectomies performed on patients with chronic Crohn's disease in this series is shown in fig 3 and is compared with our experience in elective surgery for Crohn's disease.

\section{Treatment}

ABSCESS

The abscesses have been subdivided into superficial and deep abscess according to the site of presentation. Our initial surgical approach has followed the site of presentation. Many of the abscesses pointing to the skin undoubtedly represent superficial extensions of deep abscesses. Superficial abscess occurred on 33 occasions and simple drainage was used in all of these. A persistent fistula followed in $28(85 \%)$. Deep abscesses were found on 26 occasions and were treated in two ways: by en bloc excision and by drainage procedures.

By 'en bloc' we mean resection in continuity of the abscess and diseased bowel from which the abscess arose. Fifteen patients were treated with this technique with only one subsequent fistula, one recurrent abscess, some wound sepsis, but no deaths.

Drainage without resection was complicated by fistulae and recurrent abscess in all 11 patients. Drainage was associated with bypass on five occasions, appendicectomy twice, and proximal ileostomy three times. In this group there was considerable wound sepsis and one death after a diverting ileostomy. 
FISTULAE

Fistulae do not close spontaneously. In the earlier years of our experience several patients had fistulae present for two to three years with occasional temporary closure but never any permanent spontaneous cure. Therefore, the surgical approach has been used increasingly early for this complication of Crohn's disease. The surgical methods used have been either conservative or radical (table II).

Conservative surgery included curettage and simple suture, a proximal diversion ileostomy, and two bypass procedures. These techniques failed dismally with only one long-term success in 27 operations and with one death. Four cases considered as failures were partially successful with an initial response but further fistulae from the site appeared two to three years after the operation. For example, one fistula which had healed following a defunctioning ileostomy recurred when it was subsequently closed.

\begin{tabular}{lclc}
\hline & No. of Operations & Success & Failure \\
\hline $\begin{array}{l}\text { Conservative Surgery } \\
\text { External fistulae }\end{array}$ & & & \\
$\begin{array}{l}\text { Simple primary } \\
\text { closure }\end{array}$ & 20 & & \\
$\begin{array}{l}\text { Proximal ileostomy } \\
\text { Bypass }\end{array}$ & 1 & 0 & 20 \\
Internal fistulae & 2 & 0 & 1 \\
Bypass & 1 & 0 & 2 \\
$\begin{array}{l}\text { Colostomy } \\
\text { Simple division }\end{array}$ & 2 & 0 & 1 \\
$\begin{array}{l}\text { Total } \\
\text { Radical Surgery }\end{array}$ & 27 & 0 & $2(1)$ \\
$\begin{array}{l}\text { External fistulae } \\
\text { En bloc excision }\end{array}$ & 35 & 1 & 0 \\
$\begin{array}{l}\text { Internal fistulae } \\
\text { En bloc excision }\end{array}$ & 15 & 1 & $26(1)$ \\
Total & 50 & & \\
\hline
\end{tabular}

Table II Fistulae in Crohn's disease treated by conservative and radical surgery
Radical surgery (see table II) implies a policy of fistula resection in continuity with affected bowel. Fifty operations of this type have been carried out with success on 42 occasions. The results have been best with external fistulae with a success rate of 32 out of 35. One death after excision of an external fistula occurred in a patient who was operated upon elsewhere; death was apparently due to postoperative respiratory failure. There were seven patients with significant wound sepsis but all were able to leave hospital within six weeks, three within four weeks. With internal fistulae (15 operations) the results were not as good, two deaths occurring due to leakage of suture lines after repair of complex fistulae and three other patients developed abscesses and later enterocutaneous fistulae but 10 were successful.

One patient with multiple resections suffered a recurrence of his fistula soon after radical surgery which left only 4 feet of jejunum but an appreciable length of colon. The fistula closed for 18 months with the use of azathioprine but then recurred.

\section{Discussion}

In this series $12 \%$ of patients developed an abscess. Most series report an incidence between 15 and $25 \%$, ie, patients who have had either excision or drainage of an abscess. Although in our series the majority of abscesses occurred in patients who had had a previous operation evidence suggests that the majority are due to recurrent disease rather than as a direct complication of the operation.

The finding of spontaneous fistulae in association with abscess in seven out of 10 cases suggests that both these conditions are part of the pathological process of slow penetration of the gut wall by a fissure ulcer. Schofield (1965) considers that abscess results from breakdown of lymph nodes.

The incidence of fistulae in this series was $17 \%$. Table III shows a comparison with other reported series. Our incidence is considerably less than that

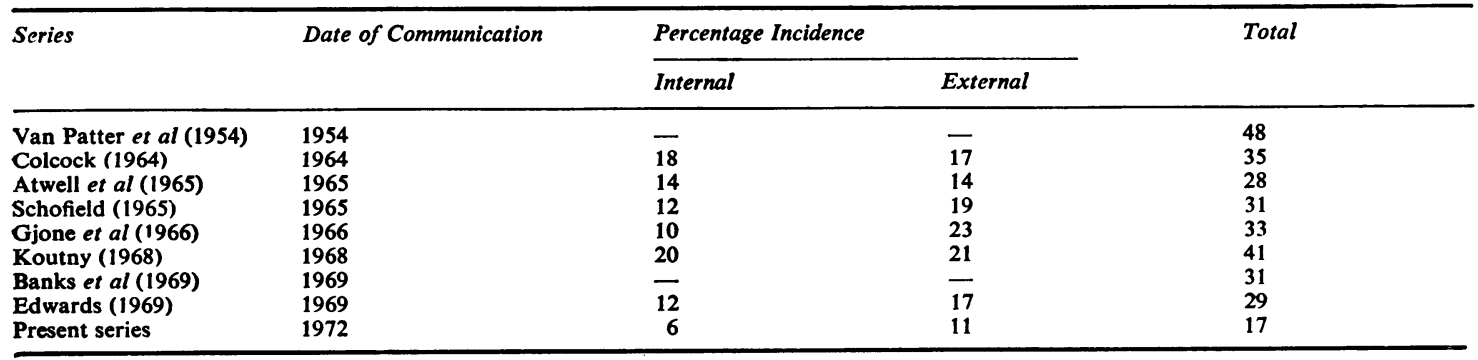

Table III Fistulae in Crohn's disease (incidence) 
in previous reports. This could be due to case selection, a higher proportion of complicated, bad-risk cases being referred to other centres. It would, however, seem more likely that patients are submitted to operative treatment at an earlier stage of their illness possibly as a result of the regular clinical, haematological, and biochemical follow up. If one considers the number of fistulae in relation to the total number of elective operations (resection and bypass) carried out over a period of 27 years (fig 2) it can be seen that while elective surgery has increased considerably the number of fistulae has remained roughly the same. This suggests that the potential complications of abscess and fistula should be considered in assessing the need for surgery in a patient with symptoms and signs of disease activity uncontrolled by medical regimes.

The true incidence of internal fistulae may be underestimated as they can be extremely difficult to recognize radiologically and often at operation. Even the pathologist can have difficulty in untangling matted loops of bowel and adequately demonstrating an internal fistula.

Of the 42 external fistulae, 36 arose from the small bowel and only six from the large bowel, a ratio of $6: 1$, whereas in the total series the approximate ratio of small bowel to large bowel disease was $3: 1$ (Fielding, 1970). The majority of fistulae primarily associated with large bowel tend to reach the exterior via the vagina probably due to the proximity of the sigmoid colon and upper rectum. Most fistulae between small and large bowel arise from primary small bowel disease and this is an important factor in considering surgical treatment. This experience is similar to that of other reported series of colonic Crohn's disease (Korelitz, 1967; Schmidt, Lennard-Jones, Morson, and Young, 1968; McGovern and Goulston, 1968).

Crohn and Yarnis (1958) have said that external abdominal fistulae do not occur if there has not been a previous abdominal operation but of the 13 fistulae that arose in patients who had never had a laparotomy in this series three were external and 10 internal.

The record of fistulae following previous operations is shown in table $\mathrm{I}$. The $5 \%$ incidence after resection is significantly less than that of $13 \%$ after bypass $(\mathrm{P}<0.025)$ as noted by previous authors (Schofield, 1965; Atwell, Duthie, and Goligher, 1965). The $24 \%$ incidence after appendicectomy only in the presence of chronic Crohn's disease is similar to that reported by Banks, Zetzel, and Richter (1969). Most of the appendicectomies were performed in the early years of our experience and only two have been performed since 1960 . This reflects a more general awareness of the possibility of Crohn's disease producing right iliac fossa pain, and that in the majority of cases it should be possible to make a clinical diagnosis. If this is so the case should be investigated and treated accordingly.

A persistent enterocutaneous fistula almost always follows simple drainage of a superficial abscess. The results of the surgical treatment appear to favour the 'en bloc' resection in the treatment of deep-seated abscess. However, some of the patients treated by drainage were critically ill and unfit for major surgery. It may well be prudent in such circumstances to drain and accept the inevitable fistula or recurrence of the abscess and deal with this when the patient's condition improves.

A success rate of $84 \%$ with a $6 \%$ mortality has followed a policy of excision surgery for Crohn's fistulae. One patient in this group received azathioprine, the use of which has been reported in patients with complex and multiple fistulae but the numbers are small and no comparable trials with surgery are available (Brooke, Javett, and Davison, 1969; Jones, Brown, Lennard-Jones, Jones, and MiltonThompson, 1969; Rhodes, Bainton, Beck, and Campbell, 1971). The severity of many of the cases in our series treated successfully by surgical excision was similar to those reported in whom azathioprine has been advocated. Surgical treatment has the advantage of removing the narrow fibrosed segment that is so often found distal to the fistula. Furthermore, the long-term risks of immunosuppressive therapy may outweigh the short-term risks of surgical resection (Penn and Starzl, 1970; Krueger, Malmgren, and Berard, 1971). In our experience of the results of surgery and our comparison with the reported results of immunosuppressive therapy, azathioprine is not a substitute for surgery as the first line of attack.

\section{References}

Atwell, J. D., Duthie, H. L., and Goligher, J. C. (1965). The outcome of Crohn's disease. Brit. J. Surg., 52, 966-972.

Banks, B. M.. Zetzel, L., and Richter, H. S. (1969). Morbidity and mortality in regional enteritis. Amer. J. dig. Dis., 14, 369-379.

Brooke, B. N., Javett, S. L., and Davison, D. W. (1970). Further experience with azathioprine for Crohn's disease. Lancet, 2, 1050-1053.

Colcock, B. P. (1964). Regional enteritis: a surgical enigma. Surg. Clin. N. Amer., 44, 779-784.

Crohn, B. B., and Yarnis, H. (1958). Regional Enteritis, 2nd ed. Grune and Stratton, New York.

Edwards, H. (1969). Crohn disease: an enquiry into its nature and consequences. Ann. roy. Coll. Surg. Engl., 44. 121-139.

Fielding. J. F. (1970). An enquiry into certain aspects of regional enteritis. MD Thesis, University College of Cork (National University of Ireland).

Gjone, E., Orning, G. O. M., and Myren, J. (1966). Crohn's disease in Norway, 1956-63. Gut, 7, 372-374.

Jones, F. A., Brown, P., Lennard-Jones, J. E., Jones, J. H., and Milton-Thompson, G. J. (1969). Azathioprine for Crohn's disease. Lancet, 2, 795.

Korelitz, B. I. (1967). Clinical course, late results, and pathological nature of inflammatory disease of the colon initially sparing the rectum. Gut, 8, 281-290. 
Koutny, J. (1968). Expérience clinique de chirugical dans 70 cas de maladie de Crohn. Acta. chir. belg., 67, 981-1010.

Krueger, G. R., Malmgren, R. A., and Berard, C. W. (1971). Malignant lymphomas and plasmacytosis in mice under prolonged immunosuppression and persistent antigenic stimulation. Transplantation, 11, 138-144.

McGovern, V. J., and Goulston, S. J. M. (1968). Crohn's disease of the colon. Gut, 9, 164-176.

Penn, I., and Starzl, T. E. (1970). Malignant lymphomas in transplantation patients: a review of the world experience. Int.Z. klin. Pharmacol., 3, 49-54.
Rhodes, J., Bainton, D., Beck, P., and Campbell, H. (1971). Controlled trial of azathioprine in Crohn's disease. Lancet, 2, 1273-1276.

Schmidt, G. T., Lennard-Jones, J. E., Morson, B. C., and Young, A. C. (1968). Crohn's disease of the colon and its distinction from diverticulitis. Gut, 9, 7-16.

Schofield, P. F. (1965). Natural history and treatment of Crohn's disease. Ann. roy. coll. Surg. Engl., 36, 258-279.

Van Patter, W. N., Bargen, J. A., Dockerty, M. E., Feldman, W. H., Mayo, C. W., and Waugh, J. M. (1954). Regional enteritis. Gastroenterology, 26, 347-450. 